\title{
Care as a many-splendored topology (including prickles)
}

Kallio Kirsi Pauliina

\author{
The angels keep their ancient places - \\ Turn but a stone and start a wing! \\ 'Tis ye, 'tis your estrangèd faces, \\ That miss the many-splendored thing. \\ (Francis Thompson, In No Strange Land)
}

In his recent critique of posthumanist thinking in political geography, Häkli (2017) pinpoints responsibility as a key dimension of politics. He warns us of the risks embedded in the ethical positioning of political agency that "is (no longer) accountable in terms of human subjectivity but rather should be seen as distributed across a range of elements and objects both human and non-human" (p.5). The present special section of Area resonates strongly with such questions concerning responsible agency, approached in the papers from various perspectives of care. Concurrently, the collection makes new spatial openings to the politics and ethics of care scholarship by underlining the relationality of caring relations and agencies, in a much broader sense than how they are typically considered. The topological approach taken up in the editorial, and one of the individual contributions (Bartos 2018), provides a potentially fruitful avenue for the development of theoretical engagements within spatially-attuned studies of care. As the editors present, "thinking topologically about the collection forcefully demonstrates that caring actions and practices ripple out into the world beyond the immediate caring relationship or the immediate moment" (Hanrahan \& Smith 2018 p.1).

While care is understood by the authors as a non-individual element of life, featured by reciprocity and situatedness, following feminist ethics, it is at once noticed that human beings - and sometimes particular individuals and groups - are key practitioners of care. As a whole, the collection signals that without reflective and active human presence, it is not reasonable to conceive of caring relations or practices in a socially sustainable sense. Care is characterized by responsibilities, the ethics and politics of which can be judged and debated by human subjects only. This, however, does not render the special section traditionally humanistic. 
Author's copy. The original article has been published in Area (online 17 July 2018, doi:

10.1111/area.12490). For citation, please use the original.

To the contrary, the editors and authors reach beyond the self-sufficient, rational, enduring individual from various dimensions, insistently contesting his (sic!) sovereignty as a sole source of affective consciousness and caring activities. In doing so, each of the papers introduces various elements, actors and environments that are fundamentally important in how care unfolds in and affects our lived realities. They emphasize caring agency as always embodied but concurrently involving "deliberately motivated actions" (Bartos 2018, p. 4) and traverse the human-non-human nexus without blurring it into a meaningless distinction, as Graddy-Lovelace (in press, p.1) portrays: “A landscape of care framework, infused with political ecology, discloses the matrix of human and beyond-human care at work in what feminist geographers call geographies of responsibility." These geographies are explored in the collection through relational theoretical frameworks that explode the traditional conceptions of care, which tend to relate it merely with small, mundane, nearby, present, feminine, cute, private, soft, kind and emotional aspects of life.

This brief discussion piece will concentrate on these elements of care, as expressed in the original articles in this special section, focusing on complex and surprising forms of care. My modest attempt is to pull together some rhyming strings from the individual contributions - that surely reverberate on their own as well - and to consider what the collection may offer for further research in geography and the neighboring research fields. While perhaps needless to say, I wish to highlight that all finding and approaches discussed here are indebted to the original articles.

\section{Lost and found responsibilities in the interstices of care}

Garrett Graddy-Lovelace's (in press) article Attending to plants: Crop diversity pre-breeding technologies as agrarian care co-opted? places an argument that "care between humans entails care for beyond-human realms" (p.1). It is made in the context of agricultural biodiversity conservation and, specifically, with regard to the technologizing global pre-breeding industry focusing on the enhancement of genetic resources for food and agriculture. In approaching these technologies and practices - both new and old - as human-led processes, Graddy-Lovelace employs a critical tone of 
Author's copy. The original article has been published in Area (online 17 July 2018, doi:

10.1111/area.12490). For citation, please use the original.

voice towards current trends of newmaterialist and posthumanist thought. She warns that "if technologies supplant humans, then conditions of the mutuality of care are undermined; the networks of reciprocity and responsibility that comprise care become tangled and curtailed" (p.1, my emphasis). Here she follows the footsteps of Abrahamsson, Bertoni, Mol and Martín (2015, p.16) who state that while "human eating depends on caring well for our food" in a complex and messy, relational world, "the key point is not so much that materialities are involved in political conundrums, but how they are involved. This is best expressed with other verbs than 'causing' and 'acting'". As one key dimension currently lost in the developing global business driven by fast profitability, Graddy-Lovelace portrays some topological elements of crop breeding: the laboratorybased breeding taking place abstractly 'anywhere and nowhere' is inseparable from the field-based phenotyping that can only happen 'somewhere'.

The focus on reciprocity in this paper is illuminating of the complex relations produced through care, or in this case tending, which become disturbed when the principle of 'raising and being raised' is not understood and appreciated. Reciprocity here involves dynamic relationships first between people and nature, which enables contextual learning, and second, between the people who share practical knowledge communally, intergenerationally, and translocally. Such 'rooted and routed knowledge' comprises "the web of multidirectional flows and connections of mutual nourishment held together with care - and/or the implications of its lack" (p.1). By losing sight of the capacities embedded in it, the evolving technological development of pre-breeding is blunting its perspectives into seemingly general knowledge that does not, however, lead to synthesizing information applicable in the various empirical contexts where it needs to be implemented. As in relationships of trust, constellations of care are easily broken but slowly fixed. Therefore, following Graddy-Lovelace's (2018) conclusion, working with local actors positioned the nodes of reciprocal care is the most sustainable, responsible, but also profitable way forward in the long run - for both human and non-human species - in developing such phenomena as agricultural biodiversity in the relational world. 
Author's copy. The original article has been published in Area (online 17 July 2018, doi: 10.1111/area.12490). For citation, please use the original.

The article by Heidi Nast (2018), Big babies: Neoliberalism, adult male breastfeeding and the marketized maternal, also discusses multifaceted caring relations and practices strongly influenced by market forces, yet in a rather different context. She directs the focus to an emerging form of porn, adult breastfeeding. Here, men are offered a paradoxical subject position, of a sexualized infant nurtured and aroused by motherly porn figures. It is difficult to imagine a figure that could better shirk all responsibilities than the innocent baby whose life is centered around the milk-filled source of care. Thus, by (willingly) adopting these subject positions men (come to) set themselves beyond the responsibility-irresponsibility nexus that appears completely irrelevant in this context, which suits well the porn business constantly seeking for new opportunities to engage people into customerships as sexual objectified subjects. Besides presenting another form of subordination towards women, this form of porn robs the men of agency as sexual beings. As "privileged consumers are increasingly infantilised", they are left with little human capacities central to ethical caring subjectivities. (p.1).

Adult breastfeeding is not the only form of infantilization in the current porn landscape and popular culture more broadly. Japanese kawaii presents perhaps the most successful example, making use of different techniques of neoteny, to fuzz and reorganize the ethics of sexual relationships. Nast (2018) argues that the development is leading towards a future where the body is divided "the comparatively privileged body [is] treated to ever more finely granulated commodity circuits of attention and care" (p. 8). Traces of the increasingly transnationalizing and pornifying popular cultures can be found nearly anywhere - from the Hello Kitty sheets that your child receives as a birthday present, in the Victorian-era (Lolitas) school party at your teenager's school, and on your way to work across the city where girly figures advertise sexy lingerie on bus stops. Who carries responsibility for any of this? People with capacities and ceaseless strength to swim against the current, states competing over each other at the global marketplace, or commercial profit-making actors?

Embodied aspects of care are at the center of Kelsey Hanrahan's (2018) paper, The spaces in between care: Considerations of connection and disconnection for subjects of care, but the losses and 
Author's copy. The original article has been published in Area (online 17 July 2018, doi: 10.1111/area.12490). For citation, please use the original.

gains of agency can again be found in different forms. She presents findings from her study in Binalobdo in northern Ghana, coming close to an autoethnographic analysis of caring relations. In this culture and community, transgenerational responsibilities of care are distributed rather differently from many Western societies (cf. McQuaid et al. forthcoming). Even if structured along certain familial and communal roles, she deems "caring as a fraught process involving the management of multiple, sometimes conflicting, responsibilities" (p.4). To show what this may mean, Hanrahan walks the reader through an occasion of dying that she was involved with, where "connections were forged across spaces of disconnect during the receipt and provision of care" (p.4, my emphasis).

Hanrahan's (2018) theoretical interest in the text is in the shaping of caring subjectivities, agencies, relations, and communities. She sees people as embodied subjects who struggle "between themselves and others," where the struggle itself represents the incoherent space in which care is created and negotiated (p.5). When spending time with the elderly dying lady in her house - with her family and community members constantly around by means of care provision - Hanrahan (2018) became entangled in complex, intergenerational negotiations of care, where Nyaa Uchain was compelled to give up her established role as a care giver. She gradually grew into the cared-for, yet not as an object but a subject of care who was very actively present, both as a body and a social self. These negotiations were made over various interstices without which care could not have taken the specific, contextual forms it did, amongst the people of kith and kin involved. Importantly, regarding the responsibility aspect, Hanrahan does not lead the analysis onto paths similar to those found within the affect literature, where bodies and things interact with each other, leading to events that 'happen' and 'emerge' from affective interactions (note the passive tense). On the contrary, here people stay at the stage, as intersubjectively forming and topologically related, partial subjects, none of whom is presented in control of the co-constitution of care (with active tense).

The concurrent presence of embodiment and will also inform the paper by Ann E. Bartos (2018), Rational spaces and relational care: Campus sexual violence, intimate geopolitics, and 
Author's copy. The original article has been published in Area (online 17 July 2018, doi: 10.1111/area.12490). For citation, please use the original.

topological polis. It engages most explicitly with spatialities of care in this collection, with the core arguments: "care is not practiced or received universally, rather it is contextual, and may not necessarily result in 'good' care for the caregiver or care-receiver" (p.2). By introducing a case of rape that became publicly known throughout the US due to the legal procedure and its politicization, Bartos (2018) suggests that some theoretical ideas embedded in 'topological polis' and 'intimate geopolitics' are useful in making better sense of the far-reaching and multidirectional ramifications of caring and uncaring acts. She encourages us to ask "why and how care happens in the spaces that it does, and who the many actors are that enable and disable that care to take place" (p.3), to broaden the geographical scope of caring agency and to trace the injustices connected to caring activities.

Bartos' (2018) article raises tricky questions over responsibility. When people's caring acts can be seen as responsible and irresponsible at the same time, as they end up supporting some people in their lives while oppressing others, is caring then something we should be more careful about and should we perhaps care less for the ones we love and the things we appreciate? Are the feelings involved in caring relations a problem rather than an asset if they make us biased regarding justice? These disturbing questions - that surely every person can present to themselves and feel anxiety about - shed light on the complex relationality of care that binds together the most intimate and the most public, here and there, now, before, and in the days to come. At the interstices of care, "engagement and negotiation, recognition and potential failure shape various caring practices" (Hanrahan \& Smith 2018 p.1), making visible the partialities and dependencies of human beings. Nevertheless, human beings are the only actors who can be held responsible for what goes around in the world, as Krause (2011) among the early critics of posthumanist thinking has emphasized. Therefore, these questions need to be asked, even if we can never respond to them in a general manner or a completely satisfactory way.

The topological approach, as introduced in the editorial of this special section, takes away the cuteness and simple goodness often associated with care. Taken together with responsibility as a crucial aspect of human agency, a topological approach sets out to challenge contemporary ideas regarding distributed political agency. As differently positioned persons and people, caring subjects 
Author's copy. The original article has been published in Area (online 17 July 2018, doi:

10.1111/area.12490). For citation, please use the original.

are fully political in all meanings of the word, and the better positioned they are in their communities and societies, the more power people can use through caring. It might therefore be just as rightly said that care is as much an evil as it is a virtue. However, as the human condition does not allow us to stop caring, and we cannot draw clear boundaries to our worlds even if we wanted to (which we often don't), we will just have to continue living in the many-splendored topologies care. This means carrying the related, albeit sometimes prickly, responsibilities, rather than turning into estrangèd faces. Therefore, and in conclusion, I deem that the best we can do is to learn more about the diverse and complicated geographies of care, and to develop better theoretical and practical tools that can be used to direct care in as just and equal ways as possible, towards more responsible futures.

\section{References}

Abrahamsson S, Bertoni F, Mol A and Martín R I 2015 Living with omega-3: New materialism and enduring concerns. Environment and Planning D: Society and Space 33 4-19

Häkli J 2017 The subject of citizenship - Can there be a posthuman civil society? Political Geography doi: 10.1016/j.polgeo.2017.08.006

Bartos A E 2018 Rational spaces and relational care: Campus sexual violence, intimate geopolitics, and topological polis Area doi:

Graddy-Lovelace G 2018 Attending to plants: Crop diversity pre-breeding technologies as agrarian care coopted? Area doi:

Hanrahan K B 2018 The spaces in between care: Considerations of connection and disconnection for subjects of care Area doi:

Krause S R 2011 Bodies in action: Corporeal agency and democratic politics. Political Theory 39 299-324

McQuaid K, Vanderbeck R M, Valentine G, Diprosed K and Liue C forthcoming 'An elephant cannot fail to carry its own ivory': Transgenerational ambivalence, infrastructure and sibling support practices in urban Uganda. Emotion, Space and Society [In Press]

Nash H 2018 Big babies: Neoliberalism, adult male breastfeeding and the marketized maternal Area doi:

Hanrahan K B and Smith C E 2018 Editorial Area doi: 